\title{
Fomento à iniciativas de economia solidária com usuários de álcool e outras drogas em situação de rua: relato de experiência
}

\author{
Promotion of solidary economy initiatives with users of alcohol \\ and other drugs in street situation: report of experience
}

\section{Fomento a iniciativas de economía solidaria con usuarios de alcohol y otras drogas en situación de calle: relato de experiência}

\author{
Isabela Aparecida de Oliveira Lussi ${ }^{1}$ \\ Thamy Eduarda Ricci ${ }^{2}$ \\ Letícia Maria Pereira ${ }^{3}$
}

\begin{abstract}
RESUMO: O presente trabalho relata a experiência de fomento de uma iniciativa de economia solidária com usuários de álcool e outras drogas que se encontravam em situação de rua e abrigados em instituição religiosa em uma cidade do interior do estado de São Paulo, no período entre 2013 e 2015. Foram utilizadas rodas de conversa como metodologia para o trabalho. Os encontros eram abertos a todos os moradores da comunidade, resultando em número flutuante de participantes por encontro. Os participantes tinham entre 17 e 62 anos e suas ocupações anteriores eram, em sua maioria, na área de construção civil e na área rural. A maior parte dos moradores da comunidade fazia uso abusivo de substâncias psicoativas. Nos encontros, foram discutidos temas acerca do trabalho e da economia solidária e, a partir disso, constituiu-se um grupo destinado a produzir artesanatos diversos, a partir da afinidade de cada um, no qual a renda obtida era administrada pelo próprio grupo. $\mathrm{O}$ escoamento dos produtos se deu principalmente com a participação de seus membros na feira de Economia Solidária que acontecia semanalmente em uma Universidade da cidade. Durante o processo de finalização das atividades, observamos que o grupo desenvolveu maior autonomia e passou a se organizar melhor coletivamente, sendo que os integrantes indicaram o desejo de continuar com as atividades, mesmo sem a presença do projeto.
\end{abstract}

Palavras-chave: Economia Solidária, População em Situação de Rua, Usuários de Álcool e Outras Drogas.

\begin{abstract}
This paper reports the experience of promoting a solidarity economy initiative with users of alcohol and other drugs that were in a street situation and housed in a religious institution in a city in the interior of the state of São Paulo, between 2013 and 2015 Wheels of conversation were used as methodology for the work. The meetings were open to all residents of the community, resulting in a floating number of participants per meeting. The participants were between 17 and 62 years old and their previous occupations were, in the majority, in the area of civil construction and in the rural area. Most of the residents of the community made abusive use of psychoactive

\footnotetext{
1 Doutora em Ciências, Docente do Departamento de Terapia Ocupacional e do Programa de Pós-graduação em Terapia Ocupacional. Universidade Federal de São Carlos (UFSCar). São Carlos, São Paulo, Brasil. E-mail: isabelalussi@ gmail.com

2 Terapeuta ocupacional. Residente no Programa de Residência Multidisciplinar em Rede de Atenção Psicossocial. Universidade Federal de São Paulo (UNIFESP). Santos, São Paulo, Brasil. E-mail: thamyricci@gmail.com

3 Terapeuta ocupacional pela UFSCar. Universidade Federal de São Carlos (UFSCar). Email: leticiapereira.to@gmail. com
}

ISSN 1982-8829 Tempus, actas de saúde colet, Brasília, 11(3), 259-272, 2017 - Epub mar, 2018 
substances. In the meetings, topics were discussed about work and solidarity economy, and from this, a group was created to produce diverse crafts, from the affinity of each one, in which the obtained income was administered by the own group. The products flow was mainly with the participation of its members in the Fair of Solidary Economy that happened weekly in a University of the city. During the process of finalizing the activities, we observed that the group developed greater autonomy and began to organize better collectively, and the members indicated the desire to continue with the activities, even without the presence of the project.

Keywords: Solidarity Economy, People in Street Population, Users of Alcohol and Other Drugs.

RESUMEN: El presente trabajo relata la experiencia de fomento de una iniciativa de economía solidaria con usuarios de alcohol y otras drogas que se encontraban en situación de calle y abrigados en institución religiosa en una ciudad del interior del estado de São Paulo en el período entre 2013 y 2015 Se utilizaron ruedas de conversación como metodología para el trabajo. Los encuentros eran abiertos a todos los habitantes de la comunidad, resultando en número flotante de participantes por encuentro. Los participantes tenían entre 17 y 62 años y sus ocupaciones anteriores eran, en su mayoría, en el área de construcción civil y en el área rural. La mayoría de los habitantes de la comunidad hacían uso abusivo de sustancias psicoactivas. En los encuentros, se discutieron temas sobre el trabajo y la economía solidaria y, a partir de eso, se constituyó un grupo destinado a producir artesanías diversas, a partir de la afinidad de cada uno, en el cual la renta obtenida era administrada por el propio grupo. El flujo de los productos se dio principalmente con la participación de sus miembros en la feria de Economía Solidaria que ocurría semanalmente en una Universidad de la ciudad. Durante el proceso de finalización de las actividades, observamos que el grupo desarrolló mayor autonomía y pasó a organizarse mejor colectivamente, siendo que los integrantes indicaron el deseo de continuar con las actividades, incluso sin la presencia del proyecto.

Palabras-clave: Economía Solidaria, Personas en Situación de Calle, Usuarios de Alcohol y Otras Drogas.

\section{INTRODUÇÃO}

A Reforma Psiquiátrica brasileira teve sua efetivação garantida em 2001, com a aprovação, no congresso nacional, da Lei Federal 10.216, conhecida como Lei Paulo Delgado, que redireciona a assistência em saúde mental, garantindo a proteção e os direitos às pessoas em sofrimento psíquico, privilegiando o oferecimento de tratamento em serviços de base territorial e comunitária, tendo como objetivo final a reinserção destas pessoas na comunidade. ${ }^{1,2}$

Desde então, diferentes serviços e programas vem sendo instaurados e executadosvoltados a alcançar as transformações na assistência em saúde mental, que permitam a redução do número de leitos psiquiátricos e o fechamento dos hospitais psiquiátricos, bem como a proposição de outras formas de cuidado, como o tratamento em meio aberto, iniciativas de inclusão social pelo trabalho, oficinas de cultura e arte nos serviços de atenção psicossocial. ${ }^{1,3,4}$

Como um dos resultados deste processo, em 2011, com a Portaria $\mathrm{n}^{0} 3.088$, foi criada a Rede de Atenção Psicossocial (RAPS), no âmbito do Sistema Único de Saúde (SUS), destinada àqueles em sofrimento ou transtorno mental e com necessidades decorrentes do uso de álcool e outras drogas. ${ }^{5}$ É importante observar que a portaria que implementa a RAPS não distingue transtorno 
mental de transtornos mentais decorrentes de álcool e outras drogas, apesar de existirem serviços diferentes em função das características da população que atendem.

A RAPS é constituída pela articulação de serviços da atenção básica em saúde, atenção psicossocial especializada, atenção de urgência e de emergência, atenção residencial de caráter transitório, atenção hospitalar e por estratégias de desinstitucionalização, formada pelos Serviços Residenciais Terapêuticos, e da reabilitação psicossocial, que é composto por iniciativas de geração de trabalho e renda, empreendimentos solidários ou cooperativas sociais. ${ }^{5}$

Saraceno ${ }^{6}$ considera a reabilitação psicossocial como um conjunto de estratégias orientadas a aumentar as oportunidades de trocas de recursos e afetos entre o sujeito e o contexto em que está inserido. Nessa perspectiva, o investimento deve ser no sentido de promover abertura de espaços de trocas, bem como de viabilizar ao sujeito o direito às relações e à participação social, processo que se dá por meio, principalmente, do fortalecimento das redes sociais, como família e comunidade e do incentivo e valorização do trabalho com sentido e valor social. A criação das cooperativas sociais, por exemplo, tem um papel importante neste processo, já que essas permitem que os sujeitos assumam seus direitos como trabalhadores e exercitem sua autonomia. ${ }^{6}$

A potencialização do trabalho como instrumento de inclusão social de usuários de serviços de saúde mental é considerada um dos principais desafios da Reforma Psiquiátrica brasileira. ${ }^{1,7}$ Como forma de superar este desafio e enfrentar a exclusão das pessoas em sofrimento psíquico do mercado de trabalho, o movimento da Reforma Psiquiátrica se aproximou do movimento da Economia Solidária, e, a partir de 2004, esses movimentos vêm dialogando entre si, produzindo importantes estratégias e dispositivos com vistas a consolidar propostas de trabalho no campo da saúde mental. ${ }^{8,2,9}$

A Economia Solidária se apresenta como alternativa ao capitalismo, marcado pelo individualismo e pela competição acirrada, pois tem por princípios a autogestão, o trabalho coletivo, a democracia, o livre acesso, a propriedade coletiva dos meios de produção, equivalência das atividades, divisão igualitária dos lucros, com direitos e deveres compartilhados, cooperação etc. e possibilita autonomia e democratização às pessoas envolvidas, pois o trabalho também é uma forma de inserção na sociedade, de exercício de cidadania a essas mesmas pessoas. ${ }^{10,1}$

Esse modelo econômico representa não só outra forma de organização do trabalho, mas se assume também como um posicionamento político, diante do desejo de construção de relações de trabalho e econômicas pautadas na solidariedade e na redução das desigualdades. ${ }^{10}$

Os empreendimentos econômicos solidários buscam desenvolver habilidades e a inserção de pessoas em situação de exclusão, promovendo a inserção dessas pessoas à sociedade e a valorização das mesmas. ${ }^{11}$ 
Dentre as pessoas que se encontram em situação de desvantagem social que podem se beneficiar da Economia Solidária como forma de inclusão no trabalho estão as pessoas em situação de rua. Para a Política Nacional para População em Situação de Rua $(\mathrm{s} / \mathrm{n})^{12}$ tal população consiste no

\footnotetext{
[...] grupo populacional heterogêneo que possui em comum a pobreza extrema, os vínculos familiares interrompidos ou fragilizados e a inexistência de moradia convencional regular, e que utiliza os logradouros públicos e as áreas degradadas como espaço de moradia e de sustento, de forma temporária ou permanente, bem como as unidades de acolhimento para pernoite temporário ou como moradia provisória.
}

Entretanto, o que se sabe é que não existe um perfil único de população, ou seja, a homogeneidade está longe de ser um padrão. Mesmo que haja características que frequentemente se repetem, como ser do sexo masculino e uma situação de extrema carência material, cada um chega a rua e desenvolve sua trajetória de maneira muito singular. ${ }^{13,14}$

No Brasil, os censos realizados adotam como referência a unidade domiciliar, o que dificulta fazer levantamentos quantitativos dessa população. Entre 2007 e 2008, realizou-se a I Pesquisa Nacional sobre a População em Situação de Rua decorrente da necessidade de levantar dados e informações concretas acerca dessa população, na tentativa de proposição de políticas públicas mais condizentes com as reais demandas da mesma. ${ }^{15}$

Esse levantamento identificou 31.922 adultos em situação de rua, considerando-se os 71 municípios pesquisados. Foi identificada maioria de homens $(82 \%)$, de pessoas com idade entre 25 e 44 anos (53\%), pardas (39,1\%), com baixo nível de renda ( $\$ 20,00$ a $\mathrm{R} \$ 80,00 /$ semanais) $(52,6 \%)$. Dos entrevistados, a maioria sabia ler e escrever (74\%). Entre a população pesquisada, $45,8 \%$ sempre viveu no município em que residiam à época da entrevista. Acerca das relações e vínculos familiares, $51,9 \%$ dos entrevistados possuíam algum parente residente na cidade onde se encontram, embora $38,9 \%$ deles não mantivessem contato com os mesmos. Das razões que os levaram pra rua, foram citados problemas com uso de álcool e outras drogas $(35,5 \%)$, desemprego $(29,8 \%)$ e conflitos familiares $(29,1 \%)$. A pesquisa ressalta que dos entrevistados, $71,3 \%$ citaram pelo menos um desses três motivos, correlacionando-os entre si ou um como consequência do outro.

Acerca das relações com o mundo do trabalho, 70,9\% dos entrevistados afirmaram exercer alguma atividade remunerada, sendo, portanto, considerados trabalhadores. Dentre as atividades realizadas, destacou-se àquelas relacionadas à coleta de materiais recicláveis $(27,5 \%)$, flanelinha $(14,1 \%)$, construção civil $(6,3 \%)$, limpeza $(4,2 \%)$ e carregador/estivador $(3,1 \%)$. Ainda, 58,6\% afirmaram ter alguma profissão. Vale ressaltar que apenas uma minoria pedia dinheiro para sobreviver $(15,7 \%)$, o que contraria o senso comum de que a grande parte dessa população se constitui de pedintes. Apenas 1,9\% dos entrevistados afirmaram estar trabalhando com carteira assinada à ocasião da entrevista, sendo que a maior parte deste total respondeu que isso ocorreu há 
muito tempo ( $50 \%$ há mais de cinco anos; $22,9 \%$ de dois a cinco anos). Dos entrevistados, $7,7 \%$ dos entrevistados nunca trabalharam com carteira assinada. ${ }^{15}$

A inserção laboral em iniciativas de economia solidária para essa população representa a possibilidade de (re)estabelecer vínculos e fortalecê-los e ter sensação de pertencimento e fixação de raízes. ${ }^{16}$

Apesar da evidente contribuição da economia solidária como alternativa de inclusão social por meio do trabalho para a população em situação de rua, ainda existem poucas práticas nesta perspectiva e, consequentemente, escassa publicação em relação ao tema.

Identificando a necessidade de ações de fomento de iniciativas de Economia Solidária voltadas a esta população em uma cidade do interior do estado de São Paulo, a equipe do Núcleo de Economia Solidária de uma Universidade da mesma cidade desenvolveu um projeto com o objetivo de sensibilizar a população em situação de rua para o envolvimento com a Economia Solidária. O projeto aconteceu em uma comunidade de caráter religioso que abriga homens em situação de rua e usuários do Centro de Atenção Psicossocial - Álcool e outras drogas (CAPSad) que não tem onde morar. A instituição não é uma clínica de reabilitação, não dispondo de atendimento especializado no próprio local.

O objetivo deste relato é apresentar as atividades desenvolvidas por este projeto, que consistiu em uma intervenção com pessoas em situação de rua abrigadas nesta instituição, que, a partir da sensibilização e do envolvimento com experiências de trabalho em empreendimentos econômicos solidários, buscou estimular o fomento à criação de um grupo autogestionário de geração de trabalho e renda.

\section{METODOLOGIA}

A estratégia geral do projeto foi produzir conhecimento científico e tecnológico visando aprofundar o debate conceitual e metodológico relativo à inclusão social pelo trabalho de pessoas em situação de desvantagem social e Economia Solidária simultaneamente à ação na realidade social e à formação de diferentes atores sociais.

O desenvolvimento deste projeto se deu em duas fases. A primeira, de 2013 a 2014, de ocorrência semanal, objetivou a sensibilização das pessoas abrigadas na instituição para o envolvimento em experiências de trabalho em empreendimentos econômicos solidários. Durante a intervenção, a metodologia utilizada foi a de rodas de conversa para discussão de temas relacionados ao trabalho. Foram utilizados diversos recursos para dinamizar os encontros e visitas técnicas a cooperativas populares da cidade. 
No período de 2014 até 2015 , a segunda fase do projeto teve por objetivo o desenvolvimento de atividades produtivas que pudessem ser comercializadas coletivamente na Feira de Economia Solidária que ocorre semanalmente em uma Universidade da cidade. O projeto, também de frequência semanal, desenvolveu-se por meio de rodas de conversa acerca dos princípios da economia solidária, com a facilitação de dinâmicas e oficinas de experimentação de técnicas ensinadas pelos próprios participantes do grupo.

O projeto foi acompanhado por supervisões semanais de toda a equipe e desenvolvido, em campo, por um técnico de incubação e duas estudantes extensionistas vinculadas ao Curso de Terapia Ocupacional da Universidade em questão.

\section{RESULTADOS E DISCUSSÃO}

A instituição religiosa onde foi desenvolvido este projeto possui filiais pelo interior do estado de São Paulo, e a sede na cidade em questão, abriga, de forma gratuita, apenas homens, em situação de rua. A instituição possuía apenas missionários religiosos em sua equipe de trabalho e não mantinha vínculos com a prefeitura ou outro órgão público, atuando nos moldes da filantropia.

Os moradores são responsáveis pela manutenção do espaço, assim como pela organização interna das tarefas. O local recebe doações de diversos gêneros e mantém uma horta criada e mantida pelos moradores. Esta instituição não estabelece tempo máximo de estadia, assim como mantém as portas abertas a novos moradores e permite o trânsito para que os mesmos possam, por exemplo, buscar trabalho, cuidado com a saúde, visitar famílias a fim de fortalecer vínculos. Assim, observa-se grande rotatividade nos moradores da comunidade, e, consequentemente, dos participantes deste projeto.

O projeto aconteceu entre dezembro de 2013 e julho de 2015, subdividindo-se em dois momentos diferentes - o primeiro entre 2013 e 2014 e o segundo, entre 2014 e 2015 . A intervenção se deu por meio de encontros abertos a todos os moradores da comunidade. Apesar do número flutuante de participantes por encontro, este se manteve em uma média de 07 a 12 participantes, com idades entre 17 a 62 anos. Ao todo, 112 pessoas participaram do projeto.

À época do projeto, nenhum morador da instituição desenvolvia atividade remunerada. Acerca de experiências prévias de trabalho, a maioria dos participantes tiveram experiências em trabalhos na construção civil e na área rural.

Durante a primeira fase do projeto, ficou evidente a demanda terapêutica desta população, uma vez que a instituição não conta com equipe para acompanhamento terapêutico. Os participantes apresentavam dificuldade em falar sobre a temática do trabalho, pois os motivos do afastamento do mesmo, fragilização das redes de suporte social e ida às ruas, em sua maioria, foram relacionados 
ao abuso de substâncias psicoativas. Portanto, para eles falar em trabalho significava possibilidade de ganho financeiro e isso representava risco de recaída.

A realidade vivenciada pelas pessoas em situação de rua é decorrente do processo de exclusão social existente no Brasil, contudo, está além da questão econômica, pois também caracteriza-se pela falta de pertencimento social, perspectivas, dificuldade de acesso à informação e perda de autoestima, acarretando problemas de saúde e saúde mental dessa população. ${ }^{17}$

O consumo de drogas esteve presente desde os primórdios da história, sendo vinculado principalmente aos rituais religiosos. Porém, foi a partir do isolamento e industrialização de princípios ativos das substâncias psicoativas, no século XIX, que uma variedade maior e mais potente de drogas tornou-se mais acessível a todas as camadas da sociedade. ${ }^{18,19}$

As primeiras intervenções do Estado em repressão às drogas datam do século $\mathrm{XX}$, tendo o Brasil como um dos países signatários de convenções internacionais para a repressão do tráfico e do uso de substâncias psicoativas, resultando na formulação de uma política nacional alinhado ao discurso proibicionista. Na década de 1970, tais intervenções passaram a ser influenciadas pela medicina, que deu subsídios teórico-científicos para legitimar o controle do uso de drogas. As pessoas que faziam uso de drogas passaram a ser, então, identificadas como doentes ou criminosas e a elas destinaram-se os manicômios para tratamento. ${ }^{19,20}$

Apenas em 2003, o país implementou a Política de Atenção aos Usuários de Álcool e outras Drogas e, para Machado e Miranda ${ }^{20}$

[...] o Ministério da Saúde reconheceu que houve um atraso histórico do Sistema Único de Saúde (SUS) na assunção da responsabilidade pelo enfrentamento de problemas associados ao consumo de álcool e outras drogas. Esse atraso remete a dois aspectos que caracterizam a história das intervenções dos governantes brasileiros na área de álcool e outras drogas: as abordagens, intervenções e políticas foram original e predominantemente desenvolvidas no campo da Justiça e da segurança pública; e as dificuldades para o enfrentamento dos problemas associados a consumo de álcool e outras drogas, na agenda da saúde pública (p. 802).

Para compreender a importância da relação entre o trabalho e o uso de substâncias psicoativas deve-se considerar as consequências do uso dessas substâncias, que podem afetar as relações de trabalho e a própria organização e desenvolvimento do trabalho como fatores que podem ser determinantes na dependência química do trabalhador. ${ }^{18}$

Carillo e Mauro ${ }^{21}$ sustentam que, apesar da multifatorialidade, as possíveis circunstâncias de vulnerabilidade no ambiente de trabalho que envolvem estresse pela função desenvolvida, precarização do espaço e estímulo a rivalidade entre entre trabalhadores podem estar relacionadas ao consumo de álcool e outras drogas. Ou seja, para muitas pessoas as situações no ambiente de trabalho podem ter sido o estopim para o uso abusivo de álcool e outras drogas. Nestes casos, o 
retorno ao trabalho também pode representar uma ameaça, um risco para recaídas.

Para $\operatorname{Araújo~}^{22}$ (p. 89), as razões de se existir uma população em situação de rua é multifatorial, pois cada um possui uma história vinculada a "questões econômicas, de migração, de desagregação familiar, de desemprego, de violência urbana, de drogadição, de alcoolismo, entre outras". Um dos principais motivos para a ida às ruas é o uso de álcool e outras drogas, além do desemprego e de desavenças familiares. ${ }^{23}$

Entretanto, apesar das dificuldades acerca da ausência de um profissional que trabalhasse as questões de saúde mental na instituição, avaliou-se que as pessoas envolvidas no projeto tinham grande potencial para o trabalho e se sensibilizaram com os princípios da economia solidária. Porém, sem o acompanhamento terapêutico se tornou mais difícil a inserção destas pessoas em empreendimentos econômicos solidários do município, pois o risco da recaída e desorganização no momento de saída da comunidade seria grande. Ao fim dessa etapa, recomendou-se que a instituição contratasse um profissional para olhar as demandas terapêuticas dos moradores da comunidade. A instituição fez parceria com uma psicóloga para atender os moradores que sentissem necessidade.

A partir desta avaliação, iniciou-se o segundo momento do projeto, no qual foram discutidos os princípios da economia solidária em contraposição aos da economia capitalista, as experiências prévias de trabalho dos participantes, as possibilidades de geração de renda e de construção de um empreendimento econômico solidário. Cabe ressaltar que o uso das substâncias psicoativas e as dificuldades no manejo do dinheiro eram temáticas comuns à maioria dos participantes e sempre permeavam as discussões.

Devido à rotatividade dos moradores da instituição, tornou-se necessária a retomada constante dos princípios da economia solidária nos encontros.

Uma das principais tarefas da atualidade é viabilizar alternativas para geração de renda para as pessoas que estão em situação de rua, e que a sociedade como um todo, incluindo as três esferas do governo, tome frente dessa tarefa. ${ }^{17}$

\footnotetext{
O desafio está em elaborar alternativas que possam adequar-se à realidade de quem vive nas ruas, especialmente que levem em conta o estágio em que as pessoas se encontram. Nessa direção, alguns projetos que têm alcançado êxito são concebidos como retomada gradual de atividade produtiva, combinando atividade laboral, repasse de renda, acompanhamento social e oferta de espaços educativos. Nesse campo, além das dificuldades das atividades em si, são encontrados sérios entraves na legislação vigente no país (p. 10) ${ }^{17}$.
}

Por meio das discussões sobre economia solidária, os participantes se familiarizaram com a temática e optaram por iniciar uma experiência de produção coletiva nos moldes da economia solidária. O grupo então elaborou oficinas de experimentações de técnicas artesanais, partindo do acúmulo de experiências dos moradores, a fim de definir um produto a ser comercializado. Durante esse período, as produções artísticas passaram por diversas facetas: obras literárias, desenho e 
pintura, produção artesanal a partir de materiais reciclados, crochê e macramê e cerâmica.

Este processo foi facilitado e influenciado pelo fato de que muitos dos participantes já havia tido, em algum momento, um contato com a produção artística. Alguns dos participantes ainda trabalhavam com tais atividades, outros não mais, e, ainda, outros voltaram a trabalhar com elas a partir das intervenções, ou começaram este contato a partir das mesmas.

Foi possível observar que as atividades ali desenvolvidas tinham duas posições diferentes na vida dos participantes: para alguns, eram atividades relacionadas ao lazer, e, para outros, atividades de trabalho. Estas diversas experiências e vivências dos participantes com relação às atividades artísticas e laborais implicaram, consequentemente, no envolvimento e postura dos participantes frente às atividades desenvolvidas por nossa intervenção.

Observamos que apenas uma pequena parte dos participantes associavam a realização destas oficinas de experimentações como uma oportunidade de (re)inserção laboral. Os demais participantes entendiam as oficinas como um espaço terapêutico e/ou como momentos de ocupação do tempo para fugir do ócio do dia a dia, apresentando uma visão do trabalho como algo terapêutico, mostrando dificuldades em pensar o trabalho como um direito.

Este aspecto também é discutido por Silva e Lussi $^{24}$ em pesquisa sobre inserção laboral com usuários da saúde mental. As autoras consideram que no Brasil é ainda muito ambíguo o caráter atribuído ao trabalho tanto por parte dos serviços de saúde mental como pelos próprios usuários, ou seja, ora é concebido como instrumento terapêutico, ora como forma única e exclusiva de conquistar e exercer cidadania.

Lussi e Morato ${ }^{25}$, em uma pesquisa com usuários de serviços de saúde mental que participavam de atividades de geração de renda, também encontraram esta associação entre trabalho, ocupação do tempo e terapia. As autoras apontam que o trabalho é visto tanto com cunho terapêutico, usando o termo terapia como sinônimo de trabalho, quanto como um meio para combater o ócio, como algo que faz parte do cotidiano e que garante algo para se fazer, por grande parte dos participantes da pesquisa, o que conduz a uma dificuldade desses sujeitos em desfrutar do trabalho com valor e direito social.

Uma experiência de inserção no trabalho por meio da economia solidária com pessoas em situação de rua identificou que existe uma participação antagônica das mesmas na economia solidária. Se por um lado, a economia solidária pode proporcionar a emancipação, a participação e o reconhecimento desses sujeitos na sociedade, por outro lado, perpassa sobre eles, uma cultura capitalista na relação da venda da força de trabalho. ${ }^{26}$

Tal população tem dificuldade de levar a frente um empreendimento solidário, pois quando pensam em uma proposta de trabalho, buscam um "emprego" na perspectiva de uma atividade econômica exercida por meio de uma relação de contrato e caracterizada 
simbolicamente pelo registro em carteira profissional (p. 8) ${ }^{26}$.

A dificuldade da população em situação de rua da apropriação da lógica do trabalho autogestionário, da decisão coletiva, da autonomia e independência dos sujeitos se relaciona, provavelmente, com a própria história das perdas sofridas. Porém, o mercado capitalista, o qual visa exclusivamente o lucro e estimula a competitividade, não inclui essa população. A economia solidária é uma alternativa qualificada para inserir essa população no mundo do trabalho de forma cautelosa e com respaldo tecnológico. ${ }^{26}$

Fomos discutindo com eles o trabalho autogestionário como direito em contraposição ao trabalho terapêutico. Aos poucos os participantes foram se apropriando desta perspectiva. No decorrer do projeto, foi possível, também, observar que a dificuldade em se relacionar com a posse e administração do dinheiro estava presente para muitos dos participantes. Este receio era também vivenciado e reforçado pela direção da comunidade religiosa que administrava a instituição, que impunha limites para este contato. Assim, por mais que a atividade de geração de renda fosse considerada positiva pelos participantes, ela o era mais por conta do processo de produção e pelas oportunidades de inclusão social, sendo que a geração de renda era colocada em segundo plano ou evitada por muitos participantes.

O envolvimento com o dinheiro é um obstáculo para a inserção de usuários de álcool e outras drogas em projetos de geração de renda, já que a posse do dinheiro pode se constituir em um fator de risco para o uso e abuso de substâncias, prejudicando o tratamento. Ainda assim, é importante a inserção destes sujeitos no trabalho, como parte importante e final da proposta da reabilitação psicossocial. ${ }^{27}$

No estudo de Oliveira ${ }^{26}$, acerca das dificuldades de inserção laboral de pessoas em situação de rua em projetos de geração de renda de Juiz de Fora-MG, a autonomia e independência do grupo foi prejudicada pela presença constante de funcionários contratados por uma associação municipal parceira dos projetos. Para a autora, essa interferência inviabilizou negociações de posicionamento frente à associação, uma vez que a mesma era responsável por todas as decisões do projeto de geração de renda, moradia, transporte e alimentação dos participantes.

O ano de 2015 se iniciou com um novo momento para o projeto, com a constituição do grupo que passou a agir de maneira mais autônoma nas decisões do coletivo. Nesta fase se deu o período de incubação do grupo autogestionário de produção e comercialização de atividades artesanais.

A partir da incubação, o grupo se fortaleceu como tal e estabeleceu regras para produção de artesanato, uso de materiais e administração do dinheiro. Ao fortalecer-se, o grupo incorporou os princípios da Economia Solidária e tornou-se protagonista nas negociações de regras com a 
instituição. As discussões permearam as relações de trabalho tanto nos moldes capitalista quanto solidário, uso de substâncias psicoativas e o manejo do dinheiro. Como a instituição não permitia que eles tivessem a posse do dinheiro enquanto estavam abrigados, foi decido pelo grupo que o recurso oriundo das vendas ia compor um fundo solidário e que cada participante teria sua retirada no momento em que saísse da instituição. Cabe ressaltar que houve uma redução no número de participantes nesta fase, com uma média de 5 a 10 por encontro.

No estudo de Ghirardi et al..$^{28}$, as autoras relatam uma proposta de intervenção que levou discussões do cooperativismo para pessoas em situação de rua, com o intuito de elaborar alternativas à exclusão social e do trabalho. O encerramento dessa proposta se deu em decorrência das faltas, resultando num progressivo afastamento das pessoas e numa desmobilização coletiva.

Assim como no estudo de Oliveira ${ }^{26}$ já citado, as autoras apontam que um fator que pode ter dificultado a adesão nas discussões e na estruturação de um projeto cooperativista é a lógica capitalista e suas representações sociais do trabalho.

Dessa forma, a organização em torno de uma cooperativa de trabalho se caracterizava para uma parcela do grupo de participantes, não como uma possibilidade de gerar trabalho e renda, mas como uma alternativa temporária, transitória, diante da situação de desemprego vigente. A necessidade de busca cotidiana por emprego era constantemente enfatizada por algumas pessoas do grupo. Assim, por vezes a discussão sobre cooperativismo adquiria um caráter irrelevante perante o reconhecimento grupal do emprego como única forma desejável de trabalho, e essa perspectiva certamente se opunha à articulação das pessoas em torno de um trabalho coletivo (p. 607) ${ }^{28}$.

Para Oliveira ${ }^{26}$, a não persistência e a consequente rotatividade dos cooperados demandam que

Os projetos de geração de trabalho e renda precisam buscar estratégias que estimulem a busca de autonomia, resgatando a cidadania e sensibilizando estes homens para o envolvimento e comprometimento com as propostas bem como potencializar a perspectiva de sujeitos (p.09) ${ }^{26}$.

Posteriormente, o grupo escolheu um nome para si, Mãos e Artes, e iniciou uma produção maior de produtos diversificados de artesanato. $\mathrm{O}$ escoamento desses produtos se deu tanto a partir de uma parceria com uma profissional da instituição, que expôs os produtos em outros locais onde trabalha, e, principalmente, a partir da participação dos membros do grupo em uma feira de economia solidária que acontece semanalmente em uma Universidade da cidade.

A existência e participação dos membros no mercado das trocas sociais voltaram a ser possíveis com as exposições dos trabalhos na feira de economia solidária. Para os participantes, o simples fato de sair da comunidade, de circular por novos espaços, as novas relações estabelecidas, constituíram-se como uma das mais significativas contribuições deste projeto. Verificamos, neste momento, a importância do trabalho com um papel social possibilitador de todas estas relações e situações. 
O trabalho é visto como um meio de satisfação pessoal e promotor de possibilidades, um elemento transformador na vida dos sujeitos, como potencializador do poder aquisitivo e da independência, como recurso emancipatório e como viabilizador e ampliador das relações sociais. ${ }^{25,29}$ O trabalho se faz, assim, como ferramenta para a inclusão social ${ }^{29}$, no sentido da reabilitação psicossocial, como uma parte de grande importância neste processo.

Com a concretização dessas ações, o grupo passou a vivenciar de uma maneira prática os conceitos da economia solidária que antes eram apenas discutidos na teoria, sinalizando inclusive, a partir de uma avaliação coletiva das atividades no momento de encerramento do projeto, o desejo de continuar participando do grupo (inclusive novos moradores da chácara demonstraram este interesse), avaliando como positiva a intervenção realizada.

\section{CONCLUSÃO}

O sistema econômico capitalista tende a excluir uma grande parcela da população que não correspondem à lógica produtivista, dentre essa parcela está a população em situação de rua que, na maioria das vezes, apresenta problemas decorrentes do uso abusivo de álcool e outras drogas, tornando-os desnecessários ao seu funcionamento. Assim, as iniciativas pautadas na Economia Solidária se apresentam como caminhos possíveis para produção de vida e garantia de direitos e participação a esta população.

Neste projeto, identificou-se a potência do trabalho na perspectiva da Economia Solidária como possibilidade de reinserção no mercado de produção e de trocas sociais, e de fortalecimento do protagonismo dos sujeitos em situações de exclusão social.

Reforça-se assim a importância do desenvolvimento de programas, estratégias e políticas públicas voltadas para o desenvolvimento de iniciativas autogestionárias de Economia Solidária para populações em situação de rua, com problemas decorrentes do uso abusivo de álcool e outras drogas e rompimento de vínculos, bem como a necessidade de maiores estudos e publicações a respeito do tema.

Este trabalho foi financiado pelo Ministério da Educação, por meio do Edital PROEXT 2013 e do Edital PROEXT 2014 e pelo Conselho Nacional de Desenvolvimento Científico e Tecnológico - CNPq - Processo n 310685/2012-5

\section{REFERÊNCIAS BIBLIOGRÁFICAS}

1. Brasil. Ministério da Saúde. Secretaria de Atenção à Saúde. Departamento de Ações Programáticas Estratégicas. Saúde mental e economia solidária: inclusão social pelo trabalho. Brasília: Editora do Ministério da Saúde, 2005.

2. Brasil. Lei n. 10.216 de 6 de abril de 2001. Dispõe sobre a proteção e os direitos das pessoas portadoras de transtornos mentais e redireciona o modelo assistencial em saúde mental. Diário Oficial da União 2001. 
3. Amarante, p. Saúde mental e atenção psicossocial. 3 ed. Rio de Janeiro: Editora Fio Cruz, 2007.

4. Amarante P, Belloni F. Ampliando o direito e produzindo cidadania. In: Pinho, KLR, et al. (Orgs.). Relatos de experiências de inclusão social pelo trabalho na saúde. São Carlos: Compacta gráfica e editora, 2014.

5. Brasil. Ministério da Saúde. Portaria $N^{\circ}$ 3.088, DE 23 de dezembro de 2011. Institui a Rede de Atenção Psicossocial para pessoas com sofrimento ou transtorno mental e com necessidades decorrentes do uso de crack, álcool e outras drogas, no âmbito do Sistema Único de Saúde. Diário Oficial da União 2011.

6. Saraceno B. Libertando identidades: da reabilitação psicossocial à cidadania possível. Belo Horizonte: Te Corá Editora/ Instituto Franco Basaglia; 2000.

7. Lussi IAO, Matsukura TS, Hahn MS. Reabilitação psicossocial: oficinas de geração de renda no contexto da saúde mental. O Mundo da Saúde (CUSC. Impresso). 2010. (34):284-290.

8. Brasil. Ministério da Saúde. Secretaria de Atenção à Saúde. Departamento de Ações Programáticas Estratégicas. Saúde mental e economia solidária: inclusão social pelo trabalho. Brasília: Editora do Ministério da Saúde, 2005.

9. Singer P, Silva RMA, Schiochet V. Economia Solidária e os desafios da superação da pobreza extrema no Plano Brasil sem Miséria. In: Campelo T, Falcão T, Costa PV. et al (Orgs.). O Brasil sem miséria. Brasília: MDS, 2014.

10. Singer, P. Economia solidária: um modo de produção e distribuição. In: Singer, P.; Souza AR. A economia solidária no Brasil: a autogestão como resposta ao desemprego. São Paulo: Contexto, 2000.

11. Azambuja LR. Os valores da economia solidária. Sociologias. 2009; 11(21): 282-317.

12. Brasil. Política nacional para Inclusão Social da População em situação de rua, Brasília, (MDS, 2008)

13. Escorel S. Vivendo de teimosos: moradores de rua da cidade do Rio de Janeiro. In: Burstyn M. No meio da rua: nômades, excluídos e viradores. Rio de Janeiro: Garamond, 2003.

14. Prates JC, Prates FC, Araújo SM. Populações em situação de rua: os processos de exclusão e inclusão precária vivenciados por esse segmento. Revista Temporalis. 2011.

15. Brasil, MDS, Pesquisa Nacional sobre a População em Situação de Rua. Brasília, MDS, 2008.

16. Domingues Jr PL. Cooperativa e a construção da cidadania da população de rua. São Paulo: Loyola, 2003.

17. Costa APM. População em situação de rua: contextualização e caracterização. Revista Virtual Textos \& Contextos. 2005; (4): 1-15.

18. Beck LM, David HMS. O abuso de drogas e o mundo do trabalho: possibilidades de atuação para o enfermeiro. Escola Anna Nery Revista Enfermagem. 2007; 4(11): 706-11.

19. Alves VS. Modelos de atenção à saúde de usuários de álcool e outras drogas: discursos políticos, saberes e práticas. Caderno Saúde Pública. 2009; 11(25): 2309-2319.

20. Machado AR, Miranda PSC. Fragmentos da história da atenção à saúde para usuários de álcool e outras drogas no Brasil: da Justiça à Saúde Pública. Hist. cienc.saude-Manguinhos. 2007; 3(14): 801-821.

21. Carillo PLL, Mauro MYC. O trabalho como fator de risco ou fator de proteção para o consumo de álcool e outras drogas. Texto Contexto Enferm. 2004; 13(2): 217-225.

22. Araújo CH. Migrações e vida nas ruas. In: Burstyn M. No meio da rua: nômades, excluídos e viradores. Rio de Janeiro: Garamond, 2003.

23. Botti NCL, Castro CG, Silva MF, Silva AK, Oliveira LC, Castro ACHOA, Fonseca LLK. Prevalência de depressão entre homens adultos em situação de rua em Belo Horizonte. J. bras. psiquiatr. 2010; 1(59): 10-16.

24. Silva MDP, Lussi IAO. Geração de renda e saúde mental: o cenário do município de São Carlos. Cad. Ter. Ocup. UFSCar. 2010; (18): 35-48.

ISSN 1982-8829 Tempus, actas de saúde colet, Brasília, 11(3), 259-272, 2017 - Epub mar, 2018 
25. Lussi IAO, Morato GG. O significado do trabalho para usuários de serviços de saúde mental inseridos em projetos de geração de renda vinculados ou não ao movimento da economia solidária. Cad. Ter. Ocup. UFSCar. 2010; 3(20): 369-380.

26. Oliveira MA. Os desafios enfrentados pela população de rua em Juiz de Fora frente a proposta da economia solidária. In: V Encontro Internacional de Economia Solidária. USP, 2007.

27. Barreto RO, Lopes FT, Paula, APP. A economia solidária na inclusão social de usuários de álcool e outras drogas: reflexões a partir da análise de experiências em Minas Gerais e São Paulo. Cadernos de Psicologia Social do Trabalho. 2013; 1(16): 41-56.

28. Ghirardi MIG, Lopes SR, Barros DD, Galvani D. Vida na rua e cooperativismo: transitando pela produção de valores. Interface - Comunic, Saúde, Educ. 2005; 18(9): 601-610.

29. Lussi IAO, Pereira MAO. Concepções sobre trabalho elaboradas por usuários de serviços de saúde mental envolvidos em projetos de inserção laboral. Rev de Ter Ocup da Univ de São Paulo. 2013; (24): 208-215.

Relato apresentado em 29/10/2017

Relato aprovado em 09/01/2018

Relato publicado no sistema em 16/04/2018

ISSN 1982-8829 Tempus, actas de saúde colet, Brasília, 11(3), 259-272, 2017 - Epub mar, 2018 